\title{
Influence of basal plane domains in the tribological behavior of graphites
}

\author{
Maria Aparecida Miranda Souza ${ }^{1,2}$, Luiz Claudio Pardini ${ }^{1,2}$
}

\author{
${ }^{1}$ Instituto Tecnológico de Aeronáutica (ITA) \\ 2 Instituto de Aeronáutica e Espaço (IAE) \\ Departamento de Ciência e Tecnologia Aeroespacial (DCTA) Pça Mal. Eduardo Gomes, 50 - V. das Acácias. São José \\ dos Campos, SP,Brazil \\ e-mail: mappsouza@hotmail.com
}

\begin{abstract}
Many dynamic engineering systems have interferences and interactions that causes wear under friction effect. Carbonaceous materials, such as polycrystalline graphites, are of great interest in engineering systems due to their inherent lubricant properties and their versatility as a material for applications in the areas of mechanics, transportation, energy systems and sensitive technologies. In this work the tribological behavior of three identical pairs, pin-on-disc, of commercial polycrystalline graphites were evaluated, in a controlled environment at $20^{\circ} \mathrm{C}$ and $50 \% \mathrm{RH}$. Results of tribological behavior were correlated considering the prevalence of basal plane, identified by polarized light optical microscopy, as a function of the tribological behavior, measured by tests with pin on disc tribometer. The results showed that the coefficient of friction behavior is directly related to the basal plane mosaic domain and the extension of the damage generated on this plane due to the contact between the tribological pair. The materials studied presented an increase in the friction coefficient values, 0,$10 ; 0 ; 13$ and 0,23 with increasing area of the basal plane mosaic domain, respectively $55 ; 64$ and $81 \%$ respectively.
\end{abstract}

Keywords: basal plane, coefficient of friction, graphite, tribological behavior

\section{INTRODUCTION}

The solid carbon materials are typically formed by monolayers of stacked graphenes. In this structure each carbon is bonded to three other carbon atoms by covalent bonds, $\mathrm{sp}^{2}$ hybridized type, similar to the benzene molecule, which juxtapose. The basic structural unit of a graphitic material is its unit cell, as shown in Figure 1. The interplanar distance $\left(\mathrm{d}_{002}\right)$ between two consecutive layers of graphene by the $\mathrm{c}$ axis is ideally 0.3354 $\mathrm{nm}$, being the interactions between layers effect by Van der Waals forces [1, 2]. Due to its inherent layered structure and lubricating characteristics, graphite is widely used in tribological systems. Graphite is a material used in the areas of mechanics, transportation, energy systems and sensitive technologies. The lubricity of graphite is not an intrinsic property, the presence of gases such as water vapor in the friction region contribute to its lubricating characteristic $[1,2]$. In vacuum environments $\left(10^{-6} \mathrm{~Pa}\right)$, the coefficient of friction can reach values between 0.4 and 0.5 [3].

Under normal environmental conditions of humidity $\left(20{ }^{\circ} \mathrm{C} / 30 \% \mathrm{RH}\right)$ the coefficient of friction of graphites is low $(0.1$ to 0.3$)[4,5,6]$. The basal planes are preferably and substantially oriented parallel to the surface. Carbon materials and graphites are low surface energy solids and when they are exposed to each other damages can occur, dangling bonds, into the basal plane, and as a consequence, higher surface energy regions are exposed resulting in enhanced surface adhesion $[5,6,7]$. The friction and wear are reduced if these regions are neutralized by the action of active gases such as water vapor. This lubricating action of humidity can be explained as a result of the interaction of the third body formed in the wear process. The interaction of a third body and the moisture form a lubricating film by physical adsorption phenomena. This effect decreases the interaction between the contact faces, reducing the adhesion between them and consequently, results in a decrease in the friction coefficient $[5,6,7]$.

The graphite tribological behavior has been the focus of many studies on its performance as lubricant in different conditions of controlled atmosphere $[4,5,6,7]$. In environments with presence of active gases, 
such as oxygen or water vapor, the coefficient of friction results in values between 0.1 and 0.3 . Under inert gas atmosphere, the graphite coefficient of friction becomes as low as 0.02 , after slow stabilization of about 2

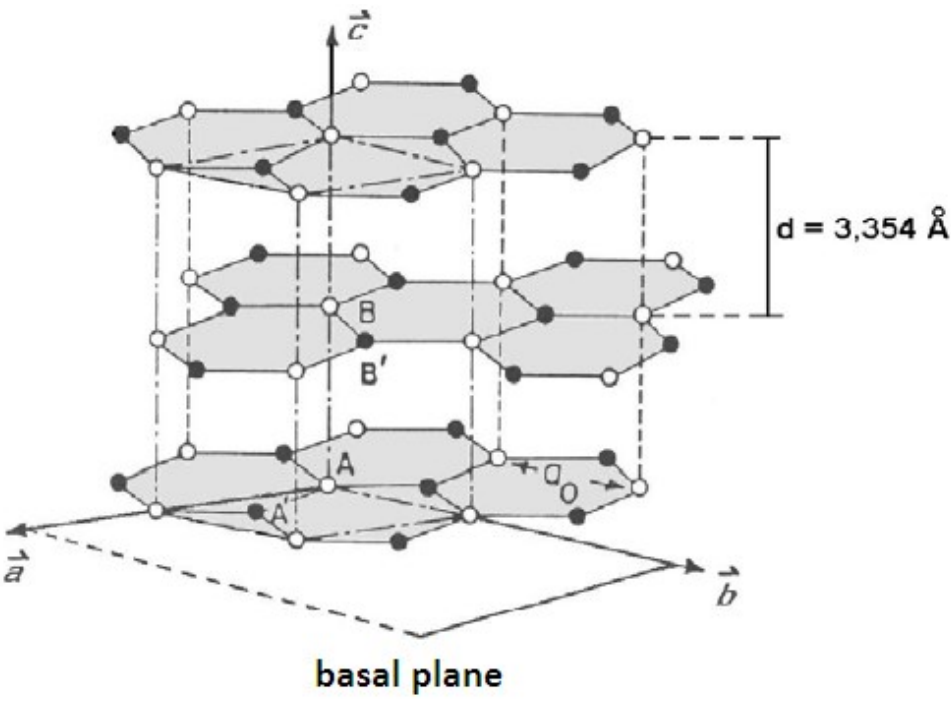

Figure 1: The hexagonal structure of graphite monocrystal [5]

hours exposure. This behavior was due to the passivation of the regions where there have been rupture of bonds in the basal plane, for the first case, and by insertion of gases between the basal planes, for the second case $[8,9]$. As a final result taking both cases is the formation of lubricating films that controls the friction and wear mechanism. Thus, in a rich moisture environment, low coefficient of friction for graphite is obtained when the basal plane becomes preferentially oriented parallel to the load surface and is covered with a lubricating film.

This work investigates the tribological behavior of extruded polycrystalline graphite, considering the influence of domain of their basal planes, determined by optical microscopy, on the coefficient of friction behavior.

\section{MATERIALS AND METHODS}

\subsection{Materials}

Commercial polycrystalline graphites were used in this work: two samples from the SGL Carbon Group (HLM 85 and HLS) and a graphite sample manufactured by TOKAY Carbon (FE 250). These materials are identified respectively as HLM, HLS and FE. The main featured characteristics of the graphite were provided by the manufacturers, as shown in Table 1 .

Table 1: Technical specifications* of the graphite, typical values, provided by manufacturers.

\begin{tabular}{c|c|c|c}
\hline MATERIAL & $\begin{array}{c}\text { DENSITY } \\
(\mathbf{g} / \mathbf{C m} 3)\end{array}$ & $\begin{array}{c}\text { GRAIN SIZE } \\
(\mathbf{m m})\end{array}$ & $\begin{array}{c}\text { YOUNG'S } \\
\text { MODULUS (GPa) }\end{array}$ \\
\hline HLM 85 & 1.75 & maximum 0.8 & $11.0^{* *}$ \\
\hline HLS & 1.81 & maximum 0.8 & $15.9^{* *}$ \\
\hline FE250 & 1.75 & average 0.8 & not reported \\
\hline
\end{tabular}

* Standard deviation was not provided

**parallel to the longitudinal direction of the grain 


\subsection{Methodology}

The characterization of these materials was performed by the determining the optical domain, perpendicular interaction and vertices, porosity, frictional coefficient $(\mu)$ and hardness. The graphitization index $(g)$ and interplanar distance were determined by X-ray diffraction (XRD). The methods are described below.

\subsubsection{Optical Microscopy (OM)}

The characterization of samples of graphite was performed by OM using an Olympus microscope with BMH with digital camera of $640 \times 480$ pixels and 24-bit.

The determination of the optical domain of graphites was performed by analyzing the optical activity of a typical section of the sample. The samples were sectioned, resin mounted, grinded and polished. The samples were analyzed by polarized light. The polarized light allows the characterization of carbonaceous materials through its interaction with the basal planes of graphite, which have random formation. In graphites clusters of graphitic domains having different directions will be found in their bulk structure. These random positions interact differently with the polarized light, giving rise to a reflective behavior displayed by a multicolored surface [10]. This allows the observation of mosaic optical domains by analyzing the surface by isolating the areas of interest. The percentage of the isolated areas in relation to the total area can so be calculated. The calculation of these areas was performed by image analysis using the Image $J$ software. Colored mosaic patterns in graphites are mainly represented by the blue and yellow colors, which are associated with the orientation edges of the basal plane positioned at $\pm 45^{\circ}$ (vertex) in relation to the polished surface of the sample. In addition, the pink color also appears which is associated with the perpendicular direction of the basal plane in relation to the incident light of the microscope. These plans in pink color are identified as isotropic mosaic planes $[10,11,12]$.

The quantification of pores was also obtained by means of quantitative image analysis, by using the Image $J$ software [12]. Pores were identified by enhancing contrast of the micrograph e by binarization of the image using 256 shades of gray.

\subsubsection{Determination of tribological behavior}

The sliding test was conducted using a pin-on-disc tribometer. The pin and disc were machined in order to provide the tribological pair. Care was taken to machine and assembly the contact surfaces both in the direction of extrusion. Figures 2 illustrate schematically the equipment set up.

The tribological test was carried in order to found the coefficient of friction between the pin and the disc $(\mu)$, as calculated according to Equation 1

$$
\mu=\frac{F a t}{F n}
$$

Where: $F a t=$ frictional force and $F n=$ normal force $(N)$

Pin-on-disc tests were performed at a tangential velocity of $0.34 \mathrm{~m} . \mathrm{s}^{-1}$, normal force of $38.3 \mathrm{~N}$, and relative humidity at $50 \pm 2 \%$ and room temperature of $20 \pm 2{ }^{\circ} \mathrm{C}$. The sliding distance was $200 \mathrm{~m}$. All pins were assembled to describe a circle of $21 \mathrm{~mm}$ diameter on a contact area of $7 \mathrm{~mm}^{2}$. The test conditions were selected according to the operational limitations imposed by the tribometer, and data (pressure values between 1 and $15 \mathrm{MPa}$ ) found in the literature for trials with pin and disc $[13,14,15,16,17]$. 


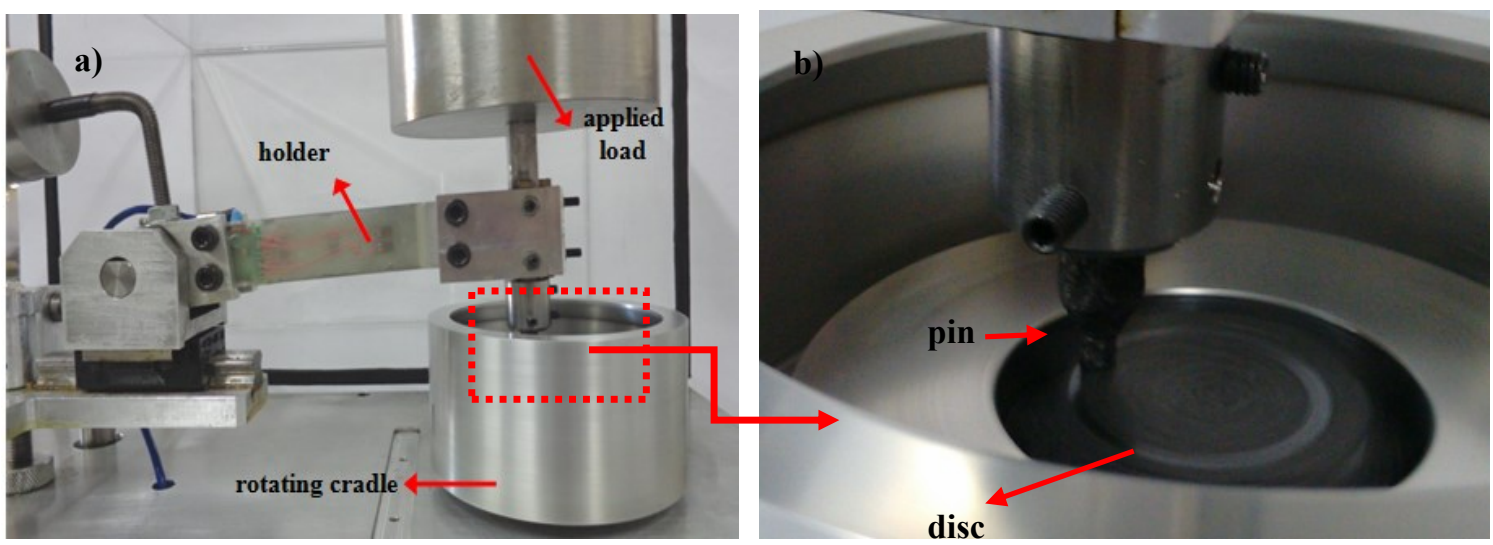

Figure 2: a) Pin and disc tribometer set up apparatus, b) assembly detail pin-on-disc

\subsubsection{Hardness}

Literature data from the manufacture's were compared in this work by measuring the Rockwell R hardness, using a 1/2 inch sphere under load of $140 \mathrm{kgf}$., according to the methodology described in ASTM D785 Method B [18].

\subsubsection{X-Ray Diffraction (XRD)}

X-ray diffraction analyzes were carried out on the X Pert Pro MPD of Panalytical equipment. The X-rays were obtained using the copper tube and Ni filter. The wavelength of the incident beam was $0.1541 \mathrm{~nm}$. A Xray diffractogram is obtained from characteristic planes of the material from which the interplanar spacing $\mathrm{d}_{002}$ is taken, which calculation is obtained by Equation 2 [19].

$d_{002}=\frac{\lambda}{2 \operatorname{sen} \theta_{002}}$

Where: $\lambda$ is the wavelength of the incident rays, $\theta_{002}=$ Bragg angle for the 002 plane.

Once $\mathrm{d}_{002}$ is determined it is possible to calculate the graphitization degree (g) from the reference values assigned to the amorphous carbon $(0.3340 \mathrm{~nm})$ and from the interplanar spacing from the unit cell of graphite (0.3354 nm), as shown in Equation 3 [20].

$g=\left[\frac{0,3440-d_{002}}{0,3440-0,3354}\right] \cdot 100$

\section{RESULTS AND DISCUSSION}

\subsection{Optical Domain and XRD}

Figure 3 shows typical micrographs obtained by polarized light optical microscopy over the cross section of FE graphite. The colors are a result of interaction from the surface of graphite and the polarized light. Isolation of colors related to the plane orientation of the FE graphite was done by using the Image J software. 


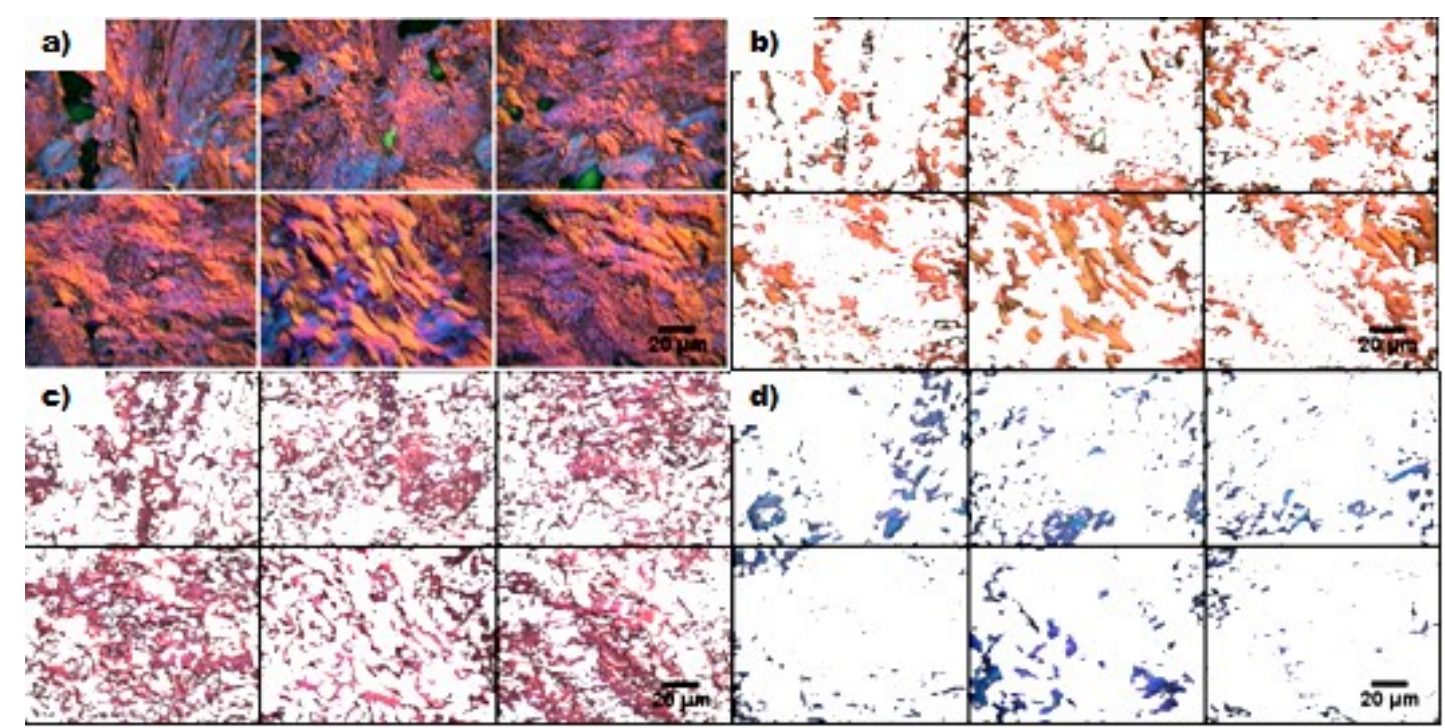

Figure 3: Typical optical Microscopy (OM) of FE graphite analyzed under polarized light. a) surface under polarized light b) and d) interaction of polarized light with basal plane oriented in $\pm 45^{\circ}$, c) perpendicular interaction of polarized light with the basal plane.

The HLS graphite presents the highest percentage $(\sim 81 \%)$ of isotropic mosaic domains among the graphite samples studied. HLM graphite exhibits an isotropic mosaic domain of $\sim 64 \%$ and the FE graphite a value of $\sim 55 \%$. This indicates that the physical contact between the faces of pin and disc will take place preferably perpendicular to the basal plane.

Table 2 shows a summary of results related to the characterization of the graphite samples. Interesting to note that the higher the percentage of optical perpendicular domain related to the basal plane, the higher is the Rockwell hardness measured. This indicates that higher percentage mosaic plain domain is related on the higher modulus (Table 1). A higher percentage of pores is found for the FE graphite ( 21\%) which is a function of the grain size (Table 1) and results in a lower density. The higher percentage of mosaic domains related to the basal plane results in a higher density and higher modulus for HLS graphite.

Table 2: Data from characterization of the resulting graphite samples

\begin{tabular}{|c|c|c|c|c|c|c|}
\hline \multirow{2}{*}{$\begin{array}{l}\text { Material } \\
\text { code }\end{array}$} & \multicolumn{2}{|c|}{ Pores } & \multirow{2}{*}{$\begin{array}{c}\text { Hardness } \\
\text { Rockwell } \\
\text { "R" }\end{array}$} & \multicolumn{2}{|c|}{ Basal plane Optical Domain (\%) } & \multirow{2}{*}{$\mathbf{g}(\%)$} \\
\hline & $\%$ & $\begin{array}{l}\text { Diâmetro } \\
\text { Feret }(\mu \mathrm{m})\end{array}$ & & $\begin{array}{c}\text { Perpendicular } \\
\text { interaction } \\
\text { (pink) }\end{array}$ & $\begin{array}{l} \pm 45^{\circ} \text { interaction, } \\
\text { vertex (yellow } \\
\text { and blue) }\end{array}$ & \\
\hline HLM & $10.7 \pm 0.8$ & $16.4 \pm 0.6$ & $86 \pm 1.0$ & $64.5 \pm 4.6$ & $35.5+3.7$ & 69.8 \\
\hline HLS & $6.47 \pm 1.1$ & $15.3 \pm 0.7$ & $105 \pm 1.0$ & $80.9 \pm 5.2$ & $19.1 \pm 4.2$ & 79.1 \\
\hline $\mathrm{FE}$ & $14.08 \pm 0.5$ & $20.8 \pm 0.5$ & $82 \pm 1.0$ & $55.1 \pm 4.7$ & $44.1 \pm 4.9$ & 58.1 \\
\hline
\end{tabular}

\subsection{Coefficient of Friction}

Figure 4 shows graphs of the coefficient of friction, $\mu$, as a function sliding distance for tribological pairs. Figure 4a shows the tribological behavior at the beginning of sliding process and Figure 4b shows de tribological behavior after steady state stage of the coefficient of friction. 

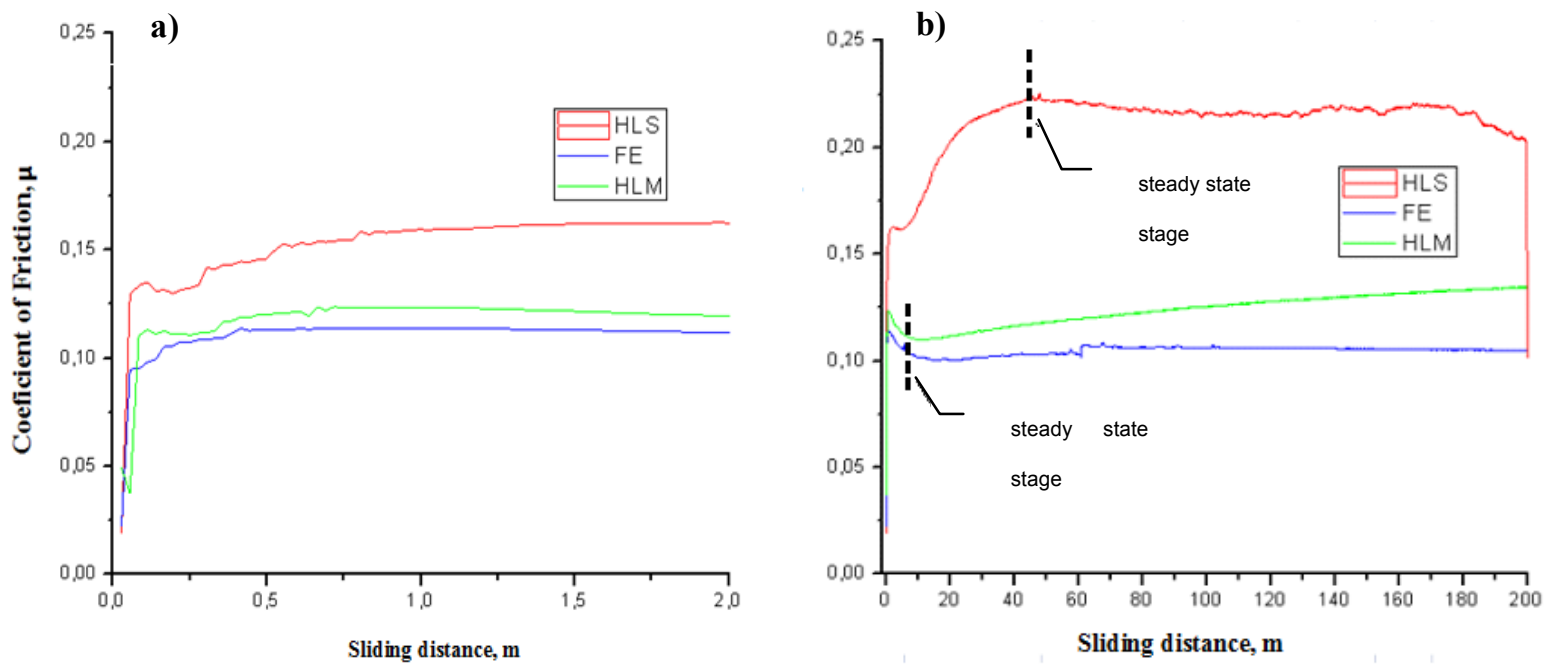

Figure 4: Evolution of friction coefficient of the pin and disc sample pairs and record the HLS samples, HLM and FE: a) Detailing the contact from beginning 0 to $2.0 \mathrm{~m}, \mathrm{~b}$ ) behavior graphic until $200 \mathrm{~m}$.

The friction coefficients from tests for the graphite studied, with values between 0.10 and 0.23 , they are in agreement with the literature. The low values are attributed to the formation of a lubricating film in between the contact surfaces $[6,7,8,9,10]$. The COF for the graphites samples (higher sliding distance) are quite different from each other. The tribological behavior of HLS graphite shows that stabilization of COF occurs at much higher sliding distance $(40 \mathrm{~m})$ in relation to HLM and FE graphites $(5 \mathrm{~m}), 0.10$ and 0.13 , respectively. HLM sample shows trend of continuous increase in the coefficient of friction.

The differences in the frictional behavior observed among the HLS sample, the FE and HLM samples can be explained by the wear progress on the basal plane. The sliding movement occur predominantly in the perpendicular position to the basal plane, mainly in the HLS sample, which can generates a stronger bonding strength between pin and disc, due to the evolution of damage caused to the connections of these planes. Consequently, an increase on the friction coefficient is noticed.

Figure 5 correlates the basal plane mosaic domain, which is perpendicular to the frictional movement between the tribological pair, in relation to the average friction coefficient, shown in Figure $4 \mathrm{~b}$. The greater is the contact between the pairs at the basal plane region, the higher is the resulting coefficient of friction.

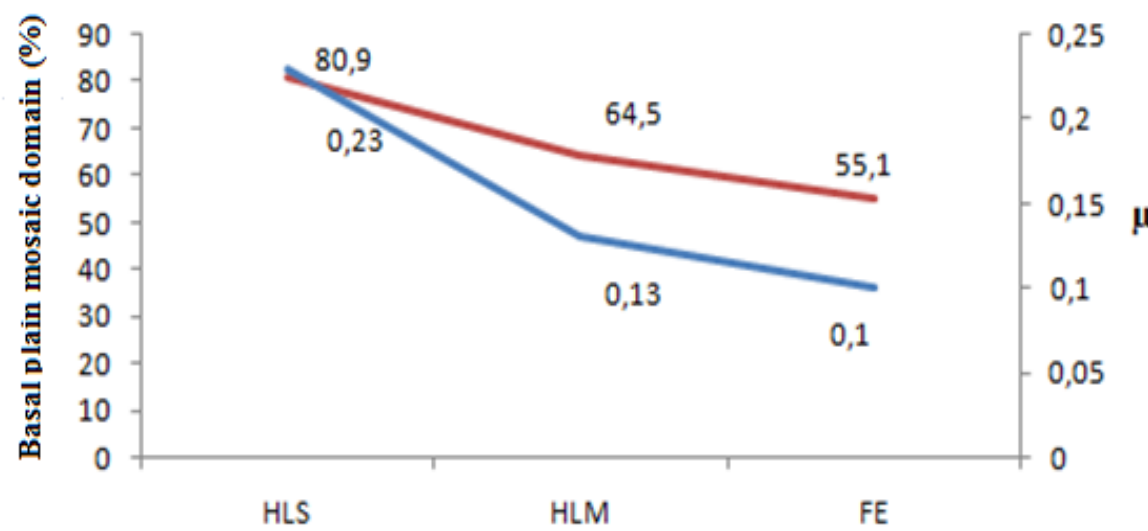

Figure 5: Coefficient of friction behavior as a function of relative proportion of the basal plane mosaic domain (\%) 


\subsection{Hardness and Stiffness}

The tribological behavior of the materials is directly related to the hardness and stiffness of a material. A low hardness material can undergo plastic deformation and leads to the generation of wear debris formed during the process of friction. Wear debris acts as a third body in the friction process. In addition, low hardness materials are more likely to form a solid lubricant film in contact with moisture, which results in stability to the friction process [20]. A continuous lubricant film cannot be formed if the wear debris fraction is too low, because the material hardness is high and has low plasticity. This feature should also be taken into consideration in order to explain the longer stabilization behavior observed in the case of HLS, considering the stiffness and hardness values found in the specifications from the manufacturers, Table 1, and hardness tests performed on the graphite samples, Table 2.

\section{CONCLUSION}

- The average coefficient of friction results found for the three samples of commercial graphite HLS, HLM and $\mathrm{FE}$ were $0.23 ; 0.13$ and 0.10 , respectively.

- The coefficient of friction is directly related to the domain of the basal plane, perpendicular to the friction plane. The higher is the amount of basal planes oriented perpendicular to the sliding pin the higher is the coefficient of friction of the pair.

- The plasticity of residues formed during the sliding couple of materials influences directly the behavior of the lubricant film, which can be analyzed by the hardness or the stiffness of the material.

\section{ACKNOWLEDGMENTS}

The authors to greatly thank to Centro de Competência em Manufatura/ Instituto Tecnológico de Aeronáutica (CCM/ITA) for allowing us the use of pin on disc tribometer.

\section{BIBLIOGRAPHY}

[1] SAVAGE, G., Carbon-carbon composites, London, Chapman \& Hall, 1993.

[2] DRESSELHAUS, M. S., DRESSELHAUS, G., EKLUND, P. C. “Carbon materials”, In: Science of Fullerenes and Carbon Nanotubes, chapter 2, San Diego, Academic Press, 1996.

[3] ZAID, H., ROBERT, F., PALMIER, D. "Influence of adsorbed gases on the surface energy of graphite: consequences on the friction behavior", Thin Solid Films, v. 264, n. 1, pp. 46-51, Aug. 1995.

[4] YEN, B. K., SCHWICKERT, B. E., TONEY, M. F., "Origin of low-friction behavior in graphite investigated by surface x-ray diffraction”, Applied Physics Letters, v. 84, n. 23, pp. 4702-4704, June, 2004.

[5] RADHIKA, R., KUMAR, N., PARDIAN, R., et al., "Structural transformation and friction behavior in turbostratic graphite sliding against Si3N4, SiC and Al2O3 balls", Surface \& Coatings Technology, v. 253, pp. 300-306, Aug. 2014.

[6] LANCASTER, J. K. "A review of the influence of environmental humidity and water on friction, lubrication and wear", Tribology International, v. 23, n. 6, pp. 371-389, Dez.1990.

[7] BERMAN, D., ERDEMIR, A. SUMANT, A.V. "Graphene: a new emerging lubricant", Materials Today, V. 17, n. 1, pp. 31-42, Jan./Feb. 2014.

[8] ZAID, H., ROBERT, F., PAULMIER, D., et al., "Correlation between the tribological behavior of graphite and its mechanical properties versus the interplanar distance”, Applied Surface Science, v. 70-71, part.1-2, pp. 103-108, June 1993.

[9] SCHMITT, M., BISTAC, S., JRADI, K. "Tribological behavior of graphite powders at nano and macroscopic scales", Journal of Physics Conference Series, v. 61, n. 1, pp. 1032-1036, Feb. 2007.

[10] MARSH, H., RODRÍGUEZ-REINOSO, F., Activated carbon. Amsterdam, Elsevier, 2006.

[11] DIAS, F. C. Uso do software image J para análise quantitativa de imagens microestruturais de materiais, Dissertação, Instituto de Pesquisas Espaciais, São José dos Campos, SP, Brasil, 2008.

[12] VON DOLLINGER, C. F. A., PARDINI, L. C., "Optical characterization of polycristaline graphites by image analisys”, In: Congresso Brasileiro de Carbono, 5., Rio de Janeiro, RJ, 25-29 April 2011. 
[13] HOKAO, M., HIRONAKAS, S., SUDA, Y., et al., "Friction and wear properties of graphite/glassy carbon composites", Wear, v. 237, n. 1, pp. 54-62, Jan. 2000.

[14] CZICHOS, H., SOUZA, M.A.M., KLAFFKE, D., et al., "Advanced in tribology: the materials point of view", Wear, v. 190, n. 2, pp. 155-161, Dec.1995.

[15] KHURSHUDOV, A.G., OLSSON, M., KATO, K. "Tribology of unlubricated sliding contact of ceramic materials and amorphous carbon", Wear, v. 205, n. 1-2, pp. 101-111, Apr. 1997.

[16] GOMES, J. R., SILVA, O.M., SILVA, C.M., et al., "The effect of sliding speed and temperature on the tribological behaviour of carbon-carbon composites", Wear, v. 249, n. 3-4, pp. 240-245, May 2001.

[17] FOUQUET, S., ROLLIN, M., PAILLER, R., et al.,"Tribological behavior of composites made carbon fibres and ceramic matrix in the Si-C system", Wear, v. 264, n. 9-10, pp. 850-856, Apr. 2008.

[18] ASTM D785-08, Standard test method for Rockwell hardness of plastics and electrical insulating materials, West Conshohocken, PA, ASTM, 2008.

[19] SHORT, M. A., WALKER Jr., P. L. "Measurement of interlayer spacings and crystal sizes in turbostratic carbons", Carbon, v.1, pp. 3-9, 1963.

[20] YU, S., ZHANG, F., XIONG, X., et al., "Tribological properties of carbon/carbon composites with various pyrolytic carbon microstructures", Wear, v. 304, n. 1-2, pp. 103-108, July 2013. 